\title{
GERD 2003 - A Consensus on the Way Ahead
}

\author{
Steven F. Moss ${ }^{a}$ David Armstrong e Rudi Arnold ${ }^{f}$ Peter Ferenci ${ }^{i} \quad$ Kwong M. Fock ${ }^{j}$ \\ Gerald Holtmanng Denis M. McCarthy ${ }^{b}$ Joaquim P. Moraes-Filhok Ernst Mutschler ${ }^{h}$ \\ Raymond Playford' Stuart J. Spechler ${ }^{c}$ Vincenzo Stanghellinim Irvin M. Modlin ${ }^{d}$ \\ aBrown University, Providence, R.I., bUniversity of New Mexico School of Medicine, Albuquerque, N. Mex., \\ c University of Texas Southwestern Medical Center, Dallas, Tex., and dYale University, New Haven, Conn., USA; \\ eMcMaster University Hamilton, Canada; fUniversity of Marburg, Marburg, gUniversity of Essen, Essen, and \\ hMainz-Hechtsheim, Germany; iUniversity Clinic for Internal Medicine, Vienna, Austria; 'Changi General Hospital, \\ Singapore; kUniversity of São Paulo Medical School, São Paulo, Brazil; 'Imperial College, University of London, \\ London, UK; m University of Bologna, Bologna, Italy
}

\section{Key Words}

Gastroesophageal reflux disease - Esophagitis . Management

\begin{abstract}
Gastroesophageal reflux disease (GERD) has in recent times become an important public health issue owing to the considerable health care resources utilized in its management, its deleterious effect on quality of life and the increasing prevalence of a relatively rare complication of reflux disease - esophageal adenocarcinoma. We review here the major current challenges in the field of reflux disease and its complications, and provide some approaches that may be useful in management. The issues to be faced include the very limited comprehension of the reasons behind the increasing prevalence of the disease, difficulties in correlating symptoms with objective data of pathological gastroesophageal reflux and the relatively unsophisticated tools we are employing to investigate the underlying pathophysiology. It is certain that the lack of well-defined and characterized methodologies to compare the effects of therapy require the development of more effective questionnaire-type analytic tools. In regard to treatment, there is little doubt that the widely prescribed proton pump inhibitors have dose-equivalent efficacy and are the most highly effective agents capable of suppressing acid, controlling many of the symptoms of GERD and healing erosions.
\end{abstract}

Nevertheless, many patients continue to experience symptoms on withdrawal or at night. Pharmacological agents that can effectively increase lower esophageal sphincter pressure or promote motility are as yet unavailable. Although the introduction of laparoscopic techniques has resulted in a modest revival in surgical intervention using a variety of 'wrap-type' operations, the indications are few and the procedure is associated with a significant morbidity and even mortality especially if the expertise of the surgeon is an issue. Endoscopic techniques of regulating reflux are at this time experimental and not applicable to the general population. Intestinal metaplasia in the lower esophagus is probably very common. Whether and how to, first, screen for, and then, perform surveillance in Barrett's esophagus remains highly problematic and contentious.

Copyright @ 2003 S. Karger AG, Basel

\section{Introduction}

Gastroesophageal reflux disease (GERD) covers a spectrum of clinical disorders resulting from reflux of the gastric contents rostrally. The condition is becoming progressively more common and is making ever more increasing demands on health service budgets. The rise of GERD in the developed world over the last 50 years has paralleled the increase in obesity and sedentary behavior of our populations and shows no signs of abating. A rare complication of reflux disease, esophageal adenocarcinoma, is also

\begin{tabular}{ll}
\hline KARGER & ( 2003 S. Karger AG, Basel \\
Fax +4161306 1234 & 0012-2823/03/0673-0111\$19.50/0 \\
$\begin{array}{l}\text { E-Mail karger@karger.ch } \\
\text { www.karger.com }\end{array}$ & $\begin{array}{l}\text { Accessible online at: } \\
\text { www.karger.com/dig }\end{array}$
\end{tabular}

Irvin M. Modlin, MD, PhD

Department of Surgery, Yale University School of Medicine

333 Cedar Street

New Haven, CT 06520-8062 (USA)

Tel. +1 203937 4785, Fax +1 203937 4783, E-Mail imodlin@optonline.net 
being diagnosed more frequently and might be the price that is being paid for the indulgent and inactive lifestyle to which we have become accustomed. A recent workshop on GERD was held at the Yale University School of Medicine in November 2002. Its purpose was to review current concepts regarding GERD and its complications, with the particular aim of highlighting those areas where there are differences of opinion and to identify topics where further research is needed. From this meeting emerged several contentious areas, such as the problems of accurately identifying the most specific symptoms of GERD and the management of patients whose symptoms are not abolished by potent acid suppression medications. The problem of esophageal and extra-esophageal nocturnal symptoms and their relationship to acid secretion, reflux, and impaired clearance of refluxate during the hours of recumbency and sleep received particular attention. Overall this text serves to concisely review the current status of GERD management as well as objectively address issues about which more understanding is required.

\section{Definitions and Symptoms}

Gastroesophageal reflux may produce erosions (erosive GERD), no overt mucosal damage (nonerosive reflux disease, or NERD) or cause atypical manifestations of reflux such as pulmonary diseases, noncardiac chest pain, reflux laryngitis or dental erosions. However, the distinction between NERD and GERD becomes less important as microscopic esophageal damage is increasingly detected by chromoendoscopy and other methods and symptoms are similar.

The typical symptom of gastroesophageal reflux is usually described as a burning sensation radiating up from the sternum. This is commonly referred to as heartburn in English-speaking countries, but in other languages there is usually no cardiac allusion. It is now becoming increasingly apparent that there is a large discrepancy between the intensity of the symptom of heartburn and the amount of acid regurgitation and objective evidence of pathological gastroesophageal reflux. Indeed, the evidence that most patients treated 'effectively' for healing of erosive esophagitis continue to have a variety of persisting symptoms demonstrates our poor understanding of the cause of many heartburn-like symptoms [1]. Whether these refractory symptoms represent 'functional heartburn' or result from reflux of gastric contents is unclear. The decision of the British Society of Gastroenterology [2] and Canadian Dyspepsia Working Group [3] to include heartburn in the definition of dyspepsia, unlike that of the Rome II criteria, suggests that the term we call 'heartburn' does not travel well across different cultures. This problem is also exemplified by the inability to identify a standard definition of GERD in a group of Scandinavian GERD patients [4].

\section{Symptom Assessment}

Lack of standardization with respect to the definition of reflux symptoms, including heartburn, and to the assessment of symptom severity continues to limit the interpretation of outcomes in studies of therapy in GERD; this is particularly true for therapeutic studies in patients with NERD, a condition in which symptom relief is the main outcome measure. There is, therefore, an urgent need for a validated instrument that can be used to identify esophageal and extraesophageal GERD symptoms accurately and, by extension, to assess the prevalence and severity of these symptoms in clinical trials and epidemiological studies.

Heartburn and acid regurgitation are generally considered to be archetypal reflux symptoms; however, although they are specific, these symptoms are not particularly sensitive for the diagnosis of GERD [5,6]. GERD can also be associated with symptoms other than heartburn and regurgitation, and the symptom complex indicative of GERD is often quite heterogeneous. This situation is complicated still further by the fact that GERD symptoms are episodic with temporal variations in severity and a variable and unpredictable response to external factors such as stress, diet and medication. This suggests strongly that GERD symptomatology might be characterized better if a more sophisticated analytical tool were available.

A measurement tool designed to monitor GERD symptom severity must account for a number of different GERD-related symptoms and also respond to the effect of temporal variations and external factors on symptom character and severity, independently of any treatment effect. In addition, it must be as brief and easy to complete as possible in order to maximize patient adherence and minimize time expenditure. There has been considerable debate about whether symptom assessment should be conducted by the patient or by an independent observer but there is, now, increasing support for a patient-based evaluation, conducted on a daily basis, to compensate for investigator and recall bias. It has, therefore, been proposed that the most effective tool for assessing and monitoring GERD symptoms is a self-administered, diary-based questionnaire, completed daily by the patient, to record the fre- 
quency and severity of symptoms and their change with time. This approach may require a precise description of the symptoms in question or it may require the presentation of 'word pictures' that describe individual symptoms and symptom clusters or 'dimensions'. It has been suggested that this approach might be facilitated by the use of an electronic diary, but it should also be noted that this particular approach has not been tested formally or validated in the context of gastroesophageal reflux disease.

To date, there has been no comprehensive tool for the assessment of reflux symptoms that could address all of the criteria listed above [7-11]. However, there is now a preliminary Hierarchical Dimension-Oriented Scale that has been designed to fulfil the criteria discussed above; this tool, known as ReQuest (Reflux Questionnaire), is currently under international evaluation to document its test characteristics in patients with NERD and erosive esophagitis [12].

\section{Pathophysiology}

There have been relatively few insights into the increasing prevalence or pathophysiology of GERD. An increased frequency of transient lower esophageal sphincter relaxations is a well-recognized feature of GERD, and the recent demonstration that transient lower esophageal sphincter relaxations may increase in the presence of a coexisting hiatal hernia [13] might explain the association of hiatal hernia with GERD. More recently described phenomena include a more distensible gastroesophageal junction in GERD patients with hernias [14] and the presence of a 'pocket' in the gastric fundus of gastric juice that is much more highly acidic than the general gastric contents, which therefore may be particularly damaging to the mucosa at the gastroesophageal junction [15].

There are many known inhibitors of transient lower esophageal sphincter relaxation, including CCK antagonists, nitric oxide synthetase inhibitors, atropine, morphine, cannabinoids, baclofen and tegaserod, and the newer members of this growing family of drugs are being actively investigated for their possible efficacy in primary or adjunctive therapy. However, the clinical utility of agents that promote lower esophageal sphincter contraction and the relative contribution of a low LES pressure to the pathogenesis of GERD remains uncertain in the absence of a specific pharmacological agent whose actions are confined to this site. Similarly, although duodenal contents and pepsin are established injurious agents for the esophageal mucosa, the efficacy of potent acid sup- pression has drawn attention away from other toxic agents in gastric contents.

As a consequence of the atypical manifestations of GERD and the association of Barrett's esophagus with esophageal adenocarcinoma, more attention has been drawn to GERD recently, which probably contributes in part to its increasing prevalence. The issue that still remains unanswered is why GERD continues to increase in prevalence? Is it only due to increased body mass in the developed world, or are our stomachs now producing more acid? Perhaps esophageal mucosal defenses are less adept than they once were? Alternatively, is the wave of novel food preservatives introduced over the last two decades finally beginning to demonstrate its biological impact?

\section{Diagnosis}

There are no gold standards in diagnosing and staging GERD. Thus the choice of a diagnostic strategy is based upon symptoms, resources and the clinical question posed. For example, in patients with alarm symptoms or who are over 50 years of age, endoscopy is clearly important to identify complications or alternative diagnoses. On the other hand, in patients with suspected extraesophageal manifestations such as non-cardiac chest pain, an empirical trial of a proton pump inhibitor (PPI) therapy or a 24hour $\mathrm{pH}$ recording study may be the most appropriate investigation. In many instances (for example in younger patients with a short history of typical symptoms), a therapeutic trial of a PPI at a high dose (often termed the 'PPI test') is sufficient to confirm a clinical diagnosis, especially in primary care. There is no consensus regarding how long this initial trial should be or the dosing strategy following a successful test. In particular, it is not established whether the PPI test has actual cost-saving advantages in practice over a strategy involving early endoscopy, as theoretically predicted from a Markov model [16].

\section{Barrett's Esophagus}

The metaplastic response of the esophageal mucosa to chronic damage, commonly known as Barrett's esophagus, is the subject of considerable attention at the moment, owing to its malignant potential. With the steady and inexorable rise in esophageal adenocarcinoma among white males in the developed world, it is important to understand the determinants responsible for the possible progression to and from Barrett's esophagus and esopha- 
geal adenocarcinoma. Controversy surrounds almost every aspect of Barrett's esophagus: its true population prevalence, its relative contribution to the development of adenocarcinoma and the rate of progression from Barrett's to dysplasia and cancer. Whether there is any strategy that may reduce the risk of progression and whether endoscopic surveillance is of any benefit in detecting lesions at an early enough stage to alter the natural history of adenocarcinoma is currently unknown.

In patients being endoscoped for any reason other than GERD, Barrett's esophagus appears to be much more prevalent than was previously thought (occurring in at least $10 \%$ of patients biopsied during diagnostic endoscopy) [17]. However, community-based studies are needed to define the age-, sex- and race-related prevalences and other clinical features that may influence the risk of developing this lesion. Estimates of progression from Barrett's esophagus to adenocarcinoma of the esophagus in GERD patients have recently been down-graded to about $0.5 \%$ per year [18]. However, this figure may still be an overestimate because most esophageal adenocarcinomas present de novo in patients without a prior diagnosis of Barrett's esophagus, and in many patients Barrett's is not apparent at the time when the cancer presents.

Although there is little consensus regarding the merits of population screening to detect Barrett's, the practice in most developed countries is to survey GERD patients with Barrett's esophagus at intervals of 1-5 years, based on the hope that this will allow the detection of early cancers and thereby alter the natural history of the disease. How do we identify the small subset of Barrett's patients who may really benefit from surveillance? In the near future, studies currently in progress are likely to identify genetic markers in initial screening biopsies that will single out from a large number of patients with Barrett's the small subset at increased risk of progressing to cancer, thus justifying costly continued surveillance in this small subset.

In the absence of such information, physicians may feel under some pressure to treat patients with Barrett's metaplasia empirically with acid suppression medications. These forces derive from small studies demonstrating a normalization of a potential surrogate endpoint, such as proliferation. While the positive studies supporting such a policy are often emphasized [19], similarly designed studies that demonstrate no effect of these interventions on proliferation and other markers (including endoscopic and histological factors) do not appear to have gained much acceptance [20]. Well-conducted, large, prospective studies utilizing as endpoints the progression of intestinal metaplasia to dysplasia or cancer are needed to definitively address whether acid inhibition, anti-cyclooxygenase drugs or other potential chemo-preventive interventions are of clinical value. Hopefully, in the future, there will be risk-stratified individualized approaches to screening, to entry into surveillance programs and possibly even to treatment, based on the demographic profile of the patient or on molecular markers in the at-risk mucosa as well as at the genomic level. These markers may also include real-time indicators of the state of the esophageal mucosa using, for example, optical coherence tomography, magnification and chromo-endoscopy.

\section{Medical Therapy}

\section{Antisecretory Drugs}

Together with implementing lifestyle modifications (whenever practicable), PPIs should be given as the drugs of choice for erosive esophagitis, achieving in clinical trials healing rates of over $80 \%$ at 4 weeks - significantly higher than rates with any other medication. Several recent publications have indicated that the optimal dose for healing moderate/severe erosive esophagitis is $40 \mathrm{mg}$ of a PPI daily [21-24]. The widespread use of PPIs testifies to the symptomatic benefits that they offer also in nonerosive disease. PPIs act by covalently binding to cysteine residues in $\mathrm{H}^{+} / \mathrm{K}^{+}$ATPases (the proton pumps) in the membranes of the secretory canaliculi of parietal cells. Differences in the molecular structures of specific PPIs result in different cysteine residues being targeted. For example, all PPIs bind to cysteine 813, lansoprazole also binds to cysteine 321 and pantoprazole binds in addition to cysteine 822 . Pharmacological studies in a variety of test systems in vitro and animal and human experimental and pharmacodynamic data indicate that the ability of pantoprazole to bind to cysteine 822 may lead to a more prolonged effect $[25,26]$. Milligram for milligram, all drugs of the PPI class appear to be comparable in their clinical effects. Indeed, human studies have not revealed significant or consistent differences between PPIs with regard to clinical or endoscopic end points [27, 28]. More detailed studies involving head-to-head comparisons between the various available drugs are needed to determine whether small pharmacokinetic differences between the drugs translate into differences in clinical practice.

In comparing the results of clinical PPI trials, it may also be important to consider the metabolism of PPIs by cytochrome p450 CYP2C19. Clinically important polymorphisms of this enzyme have been described, occurring at varying frequencies in different populations. Differ- 
ences between clinical outcomes from studies performed in diverse parts of the world and an apparent failure of the drugs to control symptoms in some subjects may be explained and rationalized in some instances after a consideration of these polymorphisms [29]. Ideally, agents lacking significant pharmacological interaction with the cytochrome p450 enzymes are desirable because many GERD patients are taking numerous other drugs for coexisting disease and are at risk of drug interactions.

Because proton pumps on the parietal cell are most accessible to PPIs when acid secretion is maximally stimulated, PPIs are most efficacious in inhibiting acid secretion when taken 30-45 min before a protein-rich breakfast. However, this may not be the case for many people who no longer eat such a meal on a daily basis or for those patients with dominant nocturnal symptoms. In these instances it seems likely that a better strategy might be to take the drug before dinner instead of, or in addition to, the morning dose. Formal studies are needed to evaluate this hypothesis.

Future challenges to improving medical therapy include the problems of large-volume refluxers who experience symptoms despite reasonable neutralization of the intra-gastric $\mathrm{pH}$, and the optimal management of patients whose symptoms are predominantly nocturnal - any advantage in the addition of $\mathrm{H}_{2}$ receptor antagonists to PPI dosing is rapidly lost due to the development of tolerance [30]. In the future, the 'on demand' use of PPIs for symptoms of heartburn in patients with nonerosive reflux disease may perhaps provide reasonable symptom relief with a considerable reduction in medication use compared with daily therapy [31].

The advent of intravenous PPIs has allowed for the achievement of more profound and more sustained predictable acid suppression than achievable with oral agents, in the absence of the development of any tolerance. This may provide clinical benefit for patients suffering from severe erosive reflux disease or acute peptic ulcer bleeding who are unable to tolerate oral therapy, or for those with pathological hypersecretory conditions such as Zollinger-Ellison syndrome.

\section{Prokinetics}

The impact of impaired esophageal or gastric motility on the development of reflux symptoms is conflicting and the prokinetic agents currently available are disappointing in terms of efficacy and side-effects. Thus, except for specific patients with documented motility abnormalities, there is little role for prokinetic agents in the treatment of GERD or NERD, except perhaps as adjunctive to PPI therapy.

\section{Nonmedical Therapy}

Surgical intervention for chronic reflux symptoms has been reported to give good results when performed by experienced surgeons in major centers. However, results from patients in community hospitals, operated on by less experienced surgeons, indicate that the successful results of highly experienced surgeons are rarely achieved in contemporary practice [32]. Currently, several endoscopic techniques designed to bolster anti-reflux barriers at the gastroesophageal junction are under investigation. These methods include a variety of endoscopic suturing procedures, devices designed to cause scarring following thermal burns, and injections of inert substances into the mucosa superficial to the lower esophageal sphincter. The vast majority of publications report only short-term outcomes, often of few patients with mostly mild disease, and usually with suboptimal study designs. Unfortunately, some of these devices have already been approved for patient use, although they are not yet established as being in the patients' best interests. All these endoscopic methods should still be considered experimental, and we would strongly recommend that patients only receive such therapies in the context of well-controlled clinical trials conducted by well-trained endoscopists.

\section{Helicobacter pylori}

In the last 5 years there has been considerable interest regarding the relationship of chronic Helicobacter pylori infection to the development and course of the symptoms and complications of GERD. While in a large prospective trial, the response to therapy was significantly better in H. pylori-infected patients [33], post-hoc analysis of some large clinical studies as well as observational data led to the conclusion that there may be an inverse relationship between $H$. pylori infection and reflux esophagitis, that eradication of $H$. pylori may provoke or unmask reflux disease, and that carriage of $H$. pylori (particularly strains expressing the cag pathogenicity island) had a 'protective' role against esophageal and cardia adenocarcinoma. However, with data accumulating from studies that were designed prospectively and specifically to evaluate the relationship between H. pylori and GERD, enthusiasm for such a beneficial effect of $H$. pylori in GERD is waning. Although means of results in large groups may not be predictive of effects in individual patients, depending on the extent of their gastritis and their ability to make acid, it is likely that for most patients the presence or absence of H. pylori in the stomach has little or no influence on the development and natural history of GERD and its com- 
plications, other than an effect on anti-secretory medication requirements.

Nevertheless, there may be a need to consider the presence of $H$. pylori in patients taking long-term PPI therapy for GERD. Patients infected with H. pylori develop progression of gastritis, gastric metaplasia and dysplasia over time, and a small percentage $(<1 \%)$ get gastric cancer. Studies suggest that this progression is accelerated during long-term PPI therapy [34, 35], although this area remains controversial. Given that the development of atrophy is a relatively early marker of the gastric preneoplastic process, the fact that it develops over only a few years is of concern and intervention therefore seems prudent. Prospective studies of both larger and longer duration are needed to address this important issue as many gastroenterologists do not feel that the small theoretical risk of 'progression to cancer' justifies eradication in all $H$. pylori-infected patients, irrespective of whether they have GERD.

\section{Conclusions}

GERD is a highly prevalent disorder. It impairs quality of life and sometimes leads to life-threatening complications. Physicians treating patients with GERD need to utilize the best currently available management options cost-effectively. With regards to therapy, PPIs are excellent medications for patients who have erosive esophagitis, producing high healing rates of esophageal lesions, rapidly and with very few side-effects. Overall there is no evidence of an appreciable difference in clinical efficacy between different PPIs at equivalent doses.

A complex problem is, however, posed by the large group of patients who have nonerosive reflux disease and symptoms of heartburn. In many of these patients, establishing a diagnosis and optimizing therapy continues to cause difficulty. In the future, heterogeneity in the patient population with regards to symptoms, risk of malignancy and extra-esophageal manifestations of GERD will dictate more individualized approaches. It is likely that a better definition of the discriminating features in the patient's history and establishing alternative pharmacological and molecular-based strategies will be needed to achieve optimal symptom relief and resource utilization. However, in NERD as in GERD, the goal of therapy is for the patient to be completely symptom free.

The development of agents with a more rapid onset of action than traditional PPIs and better methods to control nocturnal symptoms and problems related to the volume of refluxate are eagerly awaited.

\section{Appendix: List of Participants}

David Armstrong, McMaster University, Hamilton, Ontario, Canada; Rudi Arnold, University of Marburg, Germany; Robert Bell, Department of Surgery, Yale University, New Haven, Conn., USA; Marc Bigard, Service d'Hépatogastroentérologie, CHU de Nancy-Brabois, Vandœuvre-les-Nancy, France; Robert Bresalier, Gastrointestinal Cancer Research Laboratory, Henry Ford Health Sciences Center, Detroit, Mich., USA; Ronald Fass, Section of Gastroenterology, Department of Medicine, Southern Arizona VA Health Care System (1-111G-1), University of Arizona Health Sciences Center, Tucson, Ariz., USA; Peter Ferenci, University Clinic for Internal Medicine, Vienna, Austria; Kwong Ming Fock, Changi General Hospital, Singapore; Hermano Gouveia, Department of Gastroenterology, Coimbra University Hospital, Portugal; Robert Heading, Centre for Liver and Digestive Disorders, Royal Infirmary, Edinburgh, UK; Ronald Hinder, Mayo Clinic, Jacksonville, Fla., USA; Gerald Holtmann, University of Essen, Germany; Colin Howden, Feinberg School of Medicine, Northwestern University, Chicago, Ill., USA; Larry Johnson, Birmingham, Ala., USA; Peter Katelaris, Gastroenterology Unit, University of Sydney Concord Hospital, Concord, Australia; Karsten Lauritsen, Odense University Hospital, Odense, Denmark; Denis McCarthy, University of New Mexico School of Medicine, Albuquerque, N. Mex., USA; Richard McCallum, Division of Gastroenterology, University of Kansas Medical Center, Kansas City, Kans., USA; James McGuigan, Department of Medicine, University of Florida College of Medicine, Gainesville, Fla., USA; David Metz, Division of Gastroenterology, University of Pennsylvania, Philadelphia, Pa., USA; Irvin Modlin, Department of Surgery, Yale University, New Haven, Conn., USA; Joaquim P. Moraes-Filho, University of São Paulo Medical School, Brazil; Steven Moss, Brown University, Providence, R.I., USA; William Orr, Lynn Institute for Health Care Research, Oklahoma City, Okla., USA; Steven Peiken, Division of Gastroenterology and Liver Diseases, Cooper Hospital, Camden, N.J., USA; Ray Playford, Imperial College, University of London, London, UK; Lars Poulsen, Denmark; Roy Pounder, Centre for Gastroenterology, Royal Free and University College Medical School, London, UK; Joaquim Prado, São Paulo, Brazil; Eamonn Quigley, Department of Medicine, Clinical Sciences Building, Cork University Hospital, Cork, Ireland; Marie Robert, Department of Pathology, Yale University, New Haven, Conn., USA; Richard Rothstein, Department of Surgery, Dartmouth-Hitchcock Medical Center, Lebanon, N.H., USA; George Sachs, UCLA and the Wadsworth Veterans Administration Hospital, Los Angeles, Calif., USA; Eduardo Segal, Buenos Aires, Argentina; Reza Shaker, Division of Gastroenterology and Hepatology, Department of Medicine, Medical College of Wisconsin, Milwaukee, Wisc., USA; Prateek Sharma, Department of Medicine, University of Kansas School Medicine, Kansas City, Mo., USA; Stuart Spechler, University of Texas Southwestern Medical Center, Tex., USA; Vincenzo Sanghellini, University of Bologna, Bologna, Italy; Greta Taitelbaum, Harvard Medical School, Boston, Mass., USA; Akira Terano, Department of Gastroenterology, Dokkyo University School of Medicine, Tochigi, Japan; George Triadafilopoulos, Department of Gastroenterology and Hepatology, Stanford University School of Medicine, Stanford, Calif., USA; Guido Tytgat, Department of Gastroenterology, Academisch Medisch Centrum, Amsterdam, The Netherlands; Michael Wolfe, Boston, Mass., USA. 


\section{References}

1 Shaker R, Castell DO, Schoenfeld PS, Spechler $\mathrm{SJ}$ : Nighttime heartburn is an under-appreciated clinical problem that impacts sleep and daytime function. Am J Gastroenterol 2003, in press.

2 British Society of Gastroenterology Dyspepsia Management Guidelines. http://www.bsg. org.uk/clinical_prac/guidelines/dyspepsia.htm (accessed Jan 30, 2003)

3 Veldhuyzen van Zanten SJ, Flook N, Chiba N, Armstrong D, Barkun A, Bradette M, Thomson A, Bursey F, Blackshaw P, Frail D, Sinclair P: An evidence-based approach to the management of uninvestigated dyspepsia in the era of Helicobacter pylori. Canadian Dyspepsia Working Group. CMAJ 2000;162(suppl 12): S3-S23.

4 Carlsson R, Dent J, Watts R, Riley S, Sheikh R, Hatlebakk J, Haug K, de Groot G, van Oudvorst A, Dalvag A, Junghard O, Wiklund I: Gastro-oesophageal reflux disease in primary care: An international study of different treatment strategies with omeprazole. International GORD Study Group. Eur J Gastroenterol Hepatol 1998;10:119-124.

5 Galmiche JP, Bruley des Varannes S: Symptoms and disease severity in gastro-oesophageal reflux disease. Scand J Gastroenterol Suppl 1994;201:62-68.

6 Carlsson R, Holloway RH: Endoscopy-negative reflux disease. Baillières Best Pract Res Clin Gastroenterol 2000;14:827-837.

7 Damiano A, Handley K, Adler E, Siddique R, Bhattacharyja A: Measuring symptom distress and health-related quality of life in clinical trials of gastroesophageal reflux disease treatment: Further validation of the Gastroesophageal Reflux Disease Symptom Assessment Scale (GSAS). Dig Dis Sci 2002;47:1530 1537.

8 Rothman M, Farup C, Stewart W, Helbers L, Zeldis J: Symptoms associated with gastroesophageal reflux disease: Development of a questionnaire for use in clinical trials. Dig Dis Sci 2001;46:1540-1549.

9 Svedlund J, Sjodin I, Dotevall G: GSRS - A clinical rating scale for gastrointestinal symptoms in patients with irritable bowel syndrome and peptic ulcer disease. Dig Dis Sci 1988;33: 129-134.

10 Velanovich V, Vallance SR, Gusz JR, Tapia FV, Harkabus MA: Quality of life scale for gastroesophageal reflux disease. J Am Coll Surg 1996;183:217-224.

11 Velanovich V, Karmy-Jones R: Measuring gastroesophageal reflux disease: Relationship between the Health-Related Quality of Life score and physiologic parameters. Am Surg 1998;64: 649-653.
12 Mönnikes H, Bardhan KD, Stanghellini V, Berghoefer P, Armstrong D: ReQuest: Development and psychometric validation of a new evaluative symptom-scale in gastroesophageal reflux disease (GERD) (abstract). Gastroenterology 2003; 124:A535.

13 Kahrilas PJ, Shi G, Manka M, Joehl RJ: Increased frequency of transient lower esophageal sphincter relaxation induced by gastric distention in reflux patients with hiatal hernia. Gastroenterology 2000;118:688-695.

14 Pandolfino JE, Shi G, Curry J, Joehl RJ, Brasseur JG, Kahrilas PJ: Esophagogastric junction distensibility: A factor contributing to sphincter incompetence. Am J Physiol Gastrointest Liver Physiol 2002;282:G1052-G1058.

15 Fletcher J, Wirz A, Young J, Vallance R, McColl KE: Unbuffered highly acidic gastric juice exists at the gastroesophageal junction after a meal. Gastroenterology 2001;121:775783.

16 Ofman JJ, Dorn GH, Fennerty MB, Fass R: The clinical and economic impact of competing management strategies for gastro-oesophageal reflux disease. Aliment Pharmacol Ther 2002;16:261-273.

17 Shahen N: Is there a 'Barrett's iceberg?' Gastroenterology 2002; 123:636-639.

18 Shaheen NJ, Crosby MA, Bozymski EM, Sandler RS: Is there publication bias in the reporting of cancer risk in Barrett's esophagus? Gastroenterology 2000;119:333-338.

19 Castell DO: Aggressive acid control: Minimizing progression of Barrett's esophagus. Am J Manag Care 2001; 7:S15-S18.

20 Bozymski EM, Shaheen NJ: Barrett's esophagus: Acid suppression, but no regression. Am J Gastroenterol 1997;92:556-558.

21 Richter JE, Kahrilas PJ, Johanson J, Maton P, Breiter JR, Hwang C, Marino V, Hamelin B, Levine JG: Efficacy and safety of esomeprazole compared with omeprazole in GERD patients with erosive esophagitis: A randomized controlled trial. Am J Gastroenterol 2001;96:656665.

22 Koerner T, Schuetze K, Van Leendert RJ, Novais L, Bohuschke M, POEtrial Study Group: Comparable efficacy of Pantoprazole $40 \mathrm{mg}$ versus Omeprazole $40 \mathrm{mg}$ in patients with moderate to severe reflux esophagitis Results of a multinational study. Digestion 2003;67:6-13.

23 Eissele R, Gatz G, Hole U: Pantoprazole $40 \mathrm{mg}$ and esomeprazole $40 \mathrm{mg}$ show equivalent healing rates in patients with GERD (abstract). Gastroenterology 2002;122(suppl):A-582.

24 Castell DO, Kahrilas PJ, Richter JE, Vakil NB, Johnson DA, Zuckerman S, Skammer W, Levine JG: Esomeprazole (40 mg) compared with lansoprazole $(30 \mathrm{mg})$ in the treatment of erosive esophagitis. Am J Gastroenterol 2002;97: $575-583$.
25 Shin JM, Sachs G: Restoration of acid secretion following treatment with proton pump inhibitors. Gastroenterology 2002;123:15881597.

26 Katashima M, Yamamoto K, Tokuma Y, Hata T, Sawada Y, Iga T: Comparative pharmacokinetic/pharmacodynamic analysis of proton pump inhibitors omeprazole, lansoprazole and pantoprazole in humans. Eur J Drug Metab Pharmacokinet 1998;23:19-26.

27 Kromer W: Relative efficacies of gastric proton-pump inhibitors on a milligram basis: Desired and undesired SH reactions. Impact of chirality. Scand J Gastroenterol Suppl 2001; 234:3-9.

28 Yacyshyn BR, Thomson AB: The clinical importance of proton pump inhibitor pharmacokinetics. Digestion 2002;66:67-78.

29 Desta Z, Zhao X, Shin JG, Flockhart DA: Clinical significance of the cytochrome P450 2C19 genetic polymorphism. Clin Pharmacokinet 2002;41:913-958.

30 Fackler WK, Ours TM, Vaezi MF, Richter JE: Long-term effect of H2RA therapy on nocturnal gastric acid breakthrough. Gastroenterology 2002; 122:625-632.

31 Talley NJ, Venables TL, Green JR, Armstrong D, O'Kane KP, Giaffer M, Bardhan KD, Carlsson RG, Chen S, Hasselgren GS: Esomeprazole $40 \mathrm{mg}$ and $20 \mathrm{mg}$ is efficacious in the long-term management of patients with endoscopy-negative gastro-oesophageal reflux disease: A placebo-controlled trial of on-demand therapy for 6 months. Eur J Gastroenterol Hepatol 2002; 14: 857-863.

32 Vakil N, Shaw M, Kirby R: Clinical effectiveness of laparoscopic fundoplication in a U.S community. Am J Med 2003;114:1-5.

33 Holtmann G, Cain C, Malfertheiner P: Gastric Helicobacter pylori infection accelerates healing of reflux esophagitis during treatment with the proton pump inhibitor pantoprazole. Gastroenterology 1999;117:11-16.

34 Kuipers EJ, Lundell L, Klinkenberg-Knol EC, Havu N, Festen HP, Lidman B, Lamers CB, Jansen JB, Dalenback J, Snel P, Nelis GF, Meuwissen SG: Atrophic gastritis and Helicobacter pylori infection in patients with reflux esophagitis treated with omeprazole or fundoplication. N Engl J Med 1996;334:1018-1022.

35 Lundell L, Miettinen P, Myrvold HE, Pedersen SA, Thor K, Andersson A, Hattlebakk J, Havu $\mathrm{N}$, Janatuinen E, Levander K, Liedman B, Nystrom P: Lack of effect of acid suppression therapy on gastric atrophy. Nordic GERD Study Group. Gastroenterology 1999;117:319_ 326. 